Article

\title{
Fatty Acids Produced by Neofusicoccum vitifusiforme and N. paroum, Fungi Associated with Grapevine Botryosphaeria Dieback
}

\author{
Maria Michela Salvatore ${ }^{1}\left(\mathbb{D}\right.$, Selene Giambra ${ }^{2}$, Daniele Naviglio ${ }^{1}\left(\mathbb{D}\right.$, Marina DellaGreca $^{1}{ }^{(\mathbb{D}}$, \\ Francesco Salvatore ${ }^{1}$, Santella Burruano ${ }^{2}$ and Anna Andolfi ${ }^{1, *}$ \\ 1 Department of Chemical Sciences, University of Naples 'Federico II', 80126 Naples, Italy; \\ mariamichela.salvatore@unina.it (M.M.S.); naviglio@unina.it (D.N.); dellagre@unina.it (M.D.G.); \\ frsalvat@unina.it (F.S.) \\ 2 Department of Agricultural, Food and Forest Sciences (SAAF), University of Palermo, 90128 Palermo, Italy; \\ selene.giambra@unipa.it (S.G.); santella.burruano@unipa.it (S.B.) \\ * Correspondence: andolfi@unina.it; Tel.: +39-081-2539179
}

Received: 21 September 2018; Accepted: 27 November 2018; Published: 1 December 2018

\begin{abstract}
There is evidence that secondary metabolites are involved in the fungal pathogenicity and virulence of Neofusicoccum spp. Fatty acids may also influence the plant-pathogen interaction but, so far, no information is available on their production by species of Neofusicoccum associated with Botryosphaeria dieback, which is a well-known syndrome of several plants with a complex etiology. In the present paper, the production of fatty acids in liquid medium, by strains of N. vitifusiforme and N. parvum associated with declining Sicilian vine plants, was evaluated. Data, acquired via gas chromatography-mass spectrometry (GC/MS), show the presence of linoleic acid as the most abundant fatty acid produced by both examined strains. In addition, the pathogenicity of $N$. vitifusiforme was tested on 2-year-old grapevine plants of cv. Inzolia.
\end{abstract}

Keywords: Botryosphaeriaceae; grapevine trunk diseases; GC/MS; azelaic acid; linoleic acid

\section{Introduction}

Grape is a crop of major economic importance in the world: in 2016, around 7.5 Mha were under cultivation and produced $75.8 \mathrm{Mt}$ of fruits, 56\% being processed for wine, juice and spirits and $44 \%$ used for fresh or dried raisin consumption [1]. As a consequence of its relevance, grapevine disease symptoms caused by fungal pathogens are responsible for significant economic losses [2,3].

Several fungal pathogens, involved in grapevine trunk diseases (GTDs), live in and colonize the wood of the perennial organs causing wood necrosis, wood discoloration, vascular infections, and white decays [4-6]. Among the species causing GTDs, species of the family Botryosphaeriaceae have become an impending threat to productivity and longevity in most wine-growing areas by causing so-called Botryosphaeria dieback [6]. Annual losses for Botryosphaeria dieback can vary depending on wine-growing area. For instance, in the Bordeaux area (France), annual losses are estimated to be 4-20\% [7] and in some regions in China are over 30-50\% [8].

Several Botryosphaeriaceae belonging to Botryosphaeria, Diplodia, Dothiorella, Lasiodiplodia and Neofusicocum genera are associated with GTDs [9].

In Sicily, Botryosphaeria dieback has been recently associated with botryosphaeriaceous fungi, such as D. seriata, L. mediterranea, $N$. vitifusiforme and $N$. parvum $[10,11]$. Furthermore, the pathogenicity in planta of some of them (i.e., L. mediterranea and N. parvum) was newly assayed [12,13].

Botryosphaeriaceous fungi have never been isolated from leaves of infected plants [4,14]. It was hypothesized that leaf symptoms could depend on phytotoxic metabolites produced by fungi in the 
xylem, which are moved to the leaves, or induce a chain effect determining the expression of foliar symptoms [15-20]. In fact, several pathogens involved in GTDs produce secondary metabolites in vitro and in vivo whose mode of action is sometimes reported [12-16,21,22]. Many secondary metabolites (e.g., cyclohexenones, melleins, naphtalenones, and phenols) were isolated from in vitro culture of diverse species of Neofusicoccum associated with grapevine dieback $[9,14,16,18,21]$, and some of them are reported as vivotoxins [15].

Despite several studies on species of Neofusicoccum associated with grapevine dieback, the production in liquid medium of fatty acids had not been reported. In fact, fatty acids and modified fatty acids are important compounds during the colonization of plants by pathogenic fungi and may be involved in their virulence [23].

In the present study, the composition and phytotoxicity of fatty acids produced in liquid medium by strains of N. vitifusiforme [11] and N. parvum [13] were evaluated. Furthermore, the pathogenicity in planta of a grapevine strain of $N$. vitifusiforme (B8) was assayed and discussed according to data of pathogenicity previously reported for the grapevine strain of N. parvum (B19) [13].

\section{Materials and Methods}

\subsection{General Experimental Procedures}

Nuclear magnetic resonance (NMR) spectra were recorded at $400 \mathrm{MHz}$ in $\mathrm{CDCl}_{3}$ on a Bruker spectrometer (AscendTM400) (Bremen, Germany) and the same solvent was used as internal standard. All reagents and solvents were analytical grade and purchased from Carlo Erba (Milan, Italy), Sigma-Aldrich (Saint Louis, MO, USA).

Gas chromatography-mass spectrometry (GC/MS) measurements were performed with an Agilent 6850 GC (Milan, Italy) equipped with an HP-5MS capillary column (5\% phenyl methyl polysiloxane stationary phase) and the Agilent 5973 Inert MS detector (used in the scan mode). Helium was employed as the carrier gas, at a flow rate of $1 \mathrm{~mL} / \mathrm{min}$. The injector temperature was $250^{\circ} \mathrm{C}$ and, during the run, a temperature ramp raised the column temperature from $50{ }^{\circ} \mathrm{C}$ to $240{ }^{\circ} \mathrm{C}: 50^{\circ} \mathrm{C}$ for $2 \mathrm{~min} ; 10^{\circ} \mathrm{C} \mathrm{min}{ }^{-1}$ until reaching $180^{\circ} \mathrm{C}, 180^{\circ} \mathrm{C}$ for $5 \mathrm{~min}$, and $5^{\circ} \mathrm{C} \mathrm{min}^{-1}$ until reaching $240{ }^{\circ} \mathrm{C} ; 240{ }^{\circ} \mathrm{C}$ for $25 \mathrm{~min}$. The electron impact (EI) ion source was operated at $70 \mathrm{eV}$ and at $200^{\circ} \mathrm{C}$. The quadrupole mass filter was kept at $250{ }^{\circ} \mathrm{C}$ and, in the scan mode, was programmed to scan the range $45-550 \mathrm{~m} / \mathrm{z}$ at a frequency of $3.9 \mathrm{~Hz}$.

Solutions of standard compounds were prepared in $n$-hexane at a concentration range of 50-200 $\mathrm{mg} \mathrm{L}^{-1}$ and analyzed via GC/MS. Methyl ester of nonanoic acid (Sigma-Aldrich) was used as internal standard, a stock solution of which in $n$-hexane at concentration of $1 \mathrm{~g} \mathrm{~L}^{-1}$ was prepared and stored at $-20^{\circ} \mathrm{C}$.

Analytical and preparative TLCs (thin layer chromatography) were performed on silica gel plates (Kieselgel 60, $\mathrm{F}_{254}, 0.25 \mathrm{~mm}$ ) (Merck, Darmstadt, Germany). The spots were visualized by exposure to ultraviolet (UV) radiation $\left(253 \mathrm{~nm}\right.$ ), or by spraying with $10 \% \mathrm{H}_{2} \mathrm{SO}_{4}$ in $\mathrm{MeOH}$ followed by heating at $110^{\circ} \mathrm{C}$ for $10 \mathrm{~min}$. Column chromatography (CC) was performed using silica gel (Merck, Kieselgel 60, $0.063-0.200 \mathrm{~mm})$.

\subsection{Fungal Strain and Pathogenicity Test}

Strains B8 (N. vitifusiforme) and B19 (N. parvum) were isolated from stem cankers of symptomatic grapevines showing subcortical discolourations and xylematic sectorial necrosis, but in both cases without foliar symptoms, in a vineyard in western Sicily and identified in a previous study [12]. The pathogenicity of B19 strain has been reported before [13] while both pathogenicity re-isolation tests of strain B8 were performed on 2-year-old grapevine plants of cv. Inzolia in this study according to Burruano et al. [13]. 
Data of lesion length, including the non-inoculated control, were compared using the Student's $t$ test at $p<0.05$ using SAS version 9.0 (SAS Institute, Cary, NC, USA). Data obtained were expressed as mean \pm standard error (S.E.).

\subsection{Culture Filtrate Production}

The fungi were grown in stationary conditions in $2 \mathrm{~L}$ Erlenmeyer flasks containing $400 \mathrm{~mL}$ of Czapek medium amended with corn meal ( $\mathrm{pH}$ 5.7). For seeding liquid cultures, $5 \mathrm{~mL}$ of mycelial suspension by a 1-week-old colony were inoculated in each flask and incubated at $25^{\circ} \mathrm{C}$ for 4 weeks in darkness [13]. The culture filtrates were obtained by sterile filtering the culture in a vacuum on a $500 \mathrm{~mL}$ Stericup (0.45 lmHV Durapore membrane; Millipore Corp., Billerica, MA, USA) and stored at $-20{ }^{\circ} \mathrm{C}$.

\subsection{Extraction and Purification Processes}

\subsubsection{Neofusicoccum vitifusiforme}

The freeze-dried culture filtrate $(10 \mathrm{~L})$ was dissolved in ultrapure water $(1000 \mathrm{~mL})$ and extracted at native $\mathrm{pH}$ (i.e., $\mathrm{pH} \approx 6.0$ ) three times with ethyl acetate $(1000 \mathrm{~mL}$ for each). The organic phases were combined, dried with $\mathrm{Na}_{2} \mathrm{SO}_{4}$, and evaporated under reduced pressure to give the crude extract as brown-red oil (550.2 mg).

\subsubsection{Neofusicoccum parvum}

The freeze-dried culture filtrate $(3 \mathrm{~L})$ was dissolved in ultrapure water $(300 \mathrm{~mL})$ and extracted at native $\mathrm{pH}$ (i.e., $\mathrm{pH} \approx 6.5$ ) as reported before for $N$. vitifusiforme to give the crude extract as brown-red oil (495.5 mg). As previously reported [14], this extract was chromatographed through a silica gel column using as solvent system $\mathrm{CHCl}_{3}$-i-PrOH (93:7), yielding seven homogeneous fractions. The residue of second fraction $\left(23.9 \mathrm{mg}\right.$ ) was further purified by TLC on silica gel eluted with $\mathrm{CHCl}_{3}$-i-PrOH (95:5) yielding a yellowish oil (fatty acids mixture, $6.6 \mathrm{mg}, R_{\mathrm{f}} 0.50$ in the same chromatographic condition).

\subsection{Fatty Acids Methylation}

An ethereal solution of $\mathrm{CH}_{2} \mathrm{~N}_{2}$ was slowly added to $2 \mathrm{mg}$ of sample (i.e., crude extract or chromatographic fraction) dissolved in $\mathrm{MeOH}(1.5 \mathrm{~mL})$ until a yellow color was persistent. The reaction mixture was stirred at room temperature for $4 \mathrm{~h}$. The solvent was evaporated under a $\mathrm{N}_{2}$ stream and the residue used for GC/MS analysis.

\subsection{Qualitative and Quantitative Analysis of Fatty Acids}

Prompted by the collected NMR data, samples were fully analyzed by GC/MS in order to unravel the nature and amount of compounds potentially present. Before GC/MS analysis, samples were treated with diazomethane in ether in order to obtain methyl esters of fatty acids.

Methyl esters of fatty acids were identified by retention indices (RI) and their mass spectra compared with those present in databases by employing the National Institute of Standards and Technology (NIST) Mass Spectral Search Program v.2.0g which, among others, can explore the NIST 14 Mass Spectral library (2014) and the Golm Metabolome Database. Matrix components could create some problems for GC/MS identification via mass spectra and retention times essentially due to compounds' co-elution which gives rise to impure chromatographic peaks and mass spectra. In order to overcome these problems, GC/MS data were analyzed by using the NIST deconvolution program Automated Mass Spectral Deconvolution and Identification System (AMDIS) [24,25].

Quantification of individual methylated (ME) fatty acids was obtained by linear regression of the chromatographic peak areas and known concentrations of certified standards (ranging from 50 to $200 \mathrm{mg} \mathrm{L}^{-1}$ ) [26]. The response of target compounds was normalized to the response of an internal 
standard (nonanoic acid ME), which was added to the sample prior to the analysis at the constant concentration of $100 \mathrm{mg} \mathrm{L}^{-1}$.

\subsection{Phytotoxicity Bioassays}

Crude extracts and chromatographic fractions obtained both from B8 and B19 strains were tested by puncture assay on detached grapevine leaves from greenhouse two-year-old potted plants. Samples were first dissolved in $\mathrm{MeOH}$ and successively diluted in sterile distilled water, up to the assay concentrations (the final content of $\mathrm{MeOH}$ was $4 \%$ ). A droplet $(20 \mu \mathrm{L})$ of each fatty acid concentration $(0.125,0.25,0.5$, and $1 \mathrm{mg} / \mathrm{mL})$ was singly distributed on the adaxial side of leaves previously needle punctured. $\mathrm{MeOH}(4 \% v / v)$ and sterile distilled water were used as controls. Three leaves were employed as replicates and each treatment was repeated twice. The inoculated leaves were placed onto a box containing paper with $5 \mathrm{~mL}$ of water and then kept in moist chambers ( $90 \%$ relative humidity), to prevent the droplets from drying, in darkness at $25^{\circ} \mathrm{C}$ for 15 days [21]. The leaves were observed daily in order to detect any symptoms.

\section{Results}

N. vitifusiforme B8 strain showed pathogenic activity on the inoculated grapevines. Six months after inoculation, vascular discolourations were found upward and downward starting from the point of inoculation and were observed in all inoculated plants, except for control (Figure 1). Mean discolouration length produced by B8 strain was $12.0 \pm 3.0 \mathrm{~cm}$ (mean \pm S.E.) and was significantly different from the mean discolouration length resulting from the control $(0.9 \pm 0.1 \mathrm{~cm})$. The inoculated fungus was always re-isolated from each inoculated cane. The inoculated fungi were always re-isolated from the inoculated canes, but never from the control. Similar results were previously reported for N. parvum B19 [13].

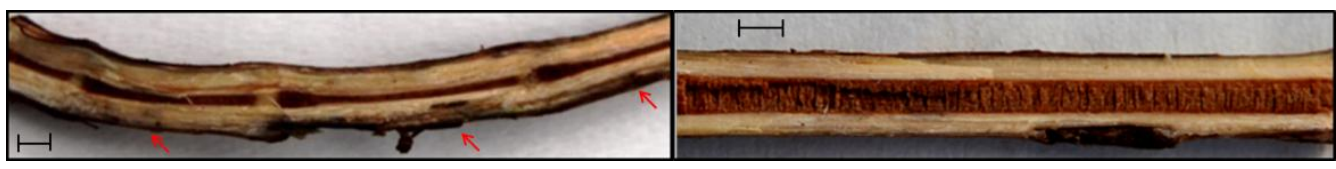

Figure 1. Brown necrosis (indicated by the red arrow) caused by N. vitifusiforme extending along a large part of the trunk of 2-year-old grapevine plants of cv. Inzolia in longitudinal section (left) and absence of xylematic symptom in the control (right). Scale bars $=1 \mathrm{~cm}$.

The preliminary spectroscopic investigation conducted for the crude extract of $N$. vitifusiforme and for the chromatographic fraction obtained from the crude extract of $N$. parvum showed typical signals of saturated and unsaturated fatty acids [27].

Samples were analyzed via GC/MS after esterification with diazomethane in ether. Table 1 is an overview of compounds (i.e., fatty acids and dicarboxylic acids) produced in liquid medium by N. vitifusiforme and N. parvum. Particularly important is the composition of the crude extract of N. vitifusiforme which presents azelaic acid.

Table 1. An overview of qualitative results of compounds (i.e., fatty acids and dicarboxylic acids) produced in liquid medium by N. vitifusiforme and N. parvum.

\begin{tabular}{ccc}
\hline & N. vitifusiforme & N. paroum \\
\hline Azelaic acid & $\checkmark$ & - \\
Palmitoleic acid & $\checkmark$ & - \\
Palmitic acid & $\checkmark$ & - \\
Linoleic acid & $\checkmark$ & $\checkmark$ \\
Elaidic acid & $\checkmark$ & $\checkmark$ \\
Stearic acid & $\checkmark$ & $\checkmark$ \\
\hline
\end{tabular}


Figure 2 shows total ion chromatograms (TICs) of each sample analyzed after treatment with diazomethane in ether. This treatment allows to identify carboxylic acids (e.g., fatty acids) as methyl esters [28]. The direct comparison of TIC profiles clearly confirms qualitative differences in fatty acid production between two species of Neofusicoccum.

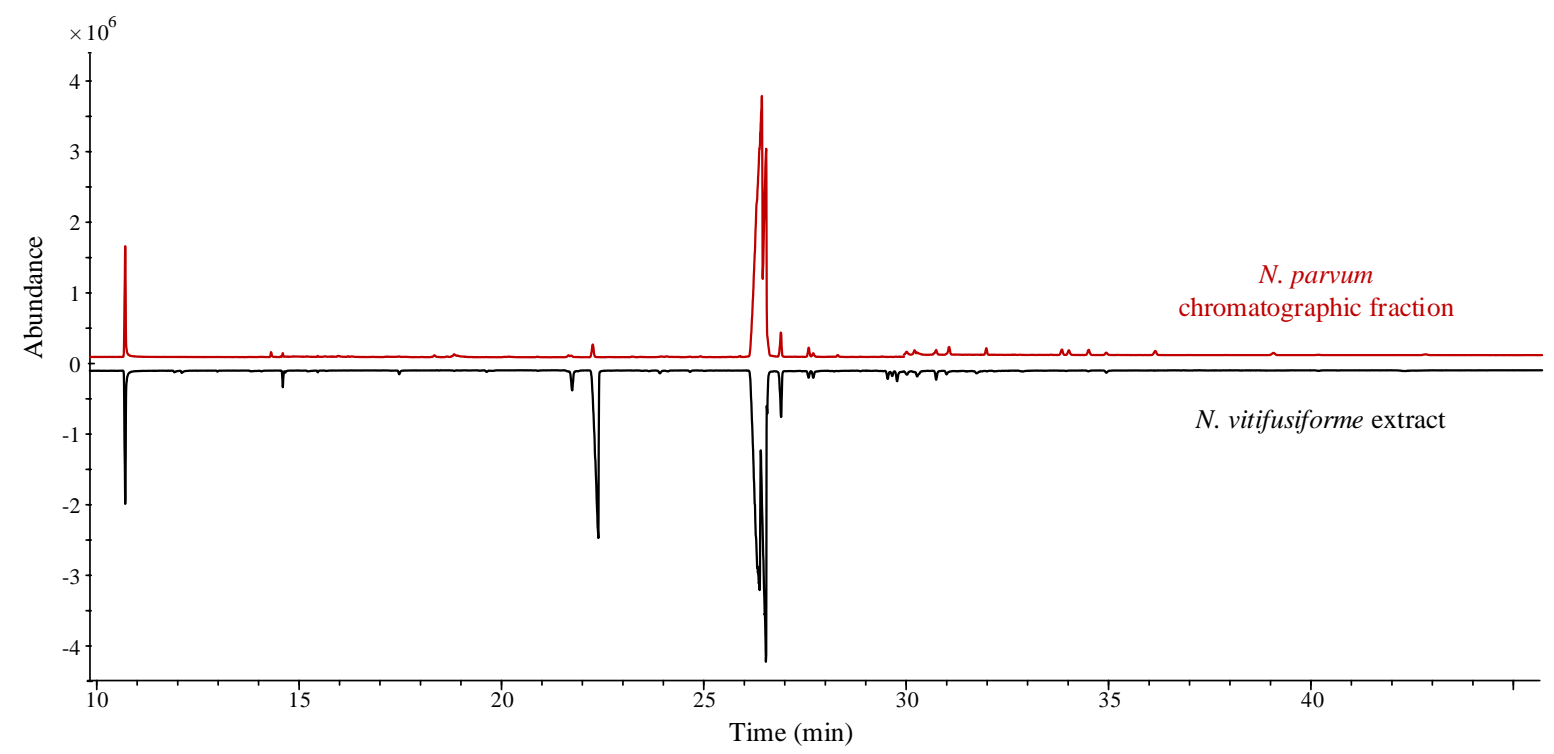

Figure 2. Head to tail comparison of total ion chromatogram (TIC) profiles of methylated compounds from N. parvum (chromatographic fraction) and N. vitifusiforme (crude extract). For clarity, chromatograms have been translated in the vertical direction by an arbitrary amount.

Finally, fatty acids, and, eventually, related compounds, in the extract of the strain B8 of N. vitifusiforme and of the strain B19 of N. parvum, have been quantified and results are summarized in Table 2 as percentages.

Table 2. Quantitative results of compounds in the extract of the strain B8 of N. vitifusiforme and of the strain B19 of N. paroum.

\begin{tabular}{ccccc}
\hline Code & Name & KI $^{\mathbf{1}}$ & $\begin{array}{c}\text { Abundance (\%) in the Extract } \\
\text { of N. vitifusiforme (B8) }\end{array}$ & $\begin{array}{c}\text { Abundance (\%) in the } \\
\text { Extract of N. parvum (B19) }{ }^{2}\end{array}$ \\
\hline- & Azelaic acid & 1548 & 0.5 & - \\
$16: 1 n-7$ & Palmitoleic acid & 1903 & 1.5 & - \\
$16: 0$ & Palmitic acid & 1926 & 10.4 & - \\
$18: 2 n-6$ & Linoleic acid & 2092 & 48.2 & 0.96 \\
$18: 1$ & Elaidic acid & 2109 & 38.0 & 0.33 \\
$18: 0$ & Stearic acid & 2125 & 1.4 & 0.01 \\
\hline
\end{tabular}

${ }^{1} \mathrm{KI}$ are referred to methyl esters of compounds reported. ${ }^{2}$ Values reported have been calculated from the composition of the chromatographic fraction which represents $1.3 \%$ of the crude extract.

From Table 2, it can be seen that linoleic acid (48.2\%) and elaidic acid (38\%), are the most abundant components in the crude extract of the strain B8 of $N$. vitifusiforme, while palmitic acid $(10.4 \%)$, palmitoleic acid $(10.5 \%)$ and stearic acid $(1.4 \%)$ are present in much lower amounts. In addition, a small amount of azelaic acid $(0.5 \%)$ was detected in the examined crude extract.

As reported by Burruano et al. [13], from the culture filtrate extract of the strain B19 of N. parvum, many naphtalenone poliketides were isolated by column chromatography and then identified via NMR spectroscopy. However, the NMR spectrum of a chromatographic fraction (representing only $1.3 \%$ of the crude extract) showed the presence of fatty acids. Accordingly, the data obtained from the fatty acids quantification in this fraction showed that linoleic acid was $73.5 \%$, elaidic acid was $25.5 \%$ and stearic acid was $0.9 \%$ (which represent, respectively, $0.96 \%, 0.33 \%$ and $0.01 \%$ of the crude extract). 
Moreover, crude extract of strain B8 of N. vitifusiforme and chromatographic fraction from crude extract of strain B19 of N. parvum did not show phytotoxic activity in puncture-assay tests on detached grapevine leaves.

\section{Discussion}

Among the fungi which are known to cause GTDs, increasing importance has been given to species from the genus Neofusicoccum [20,29]. Results obtained through inoculation of strain B8 of N. vitifusiforme and strain B19 of N. parvum [13] on grapevine cv. Inzolia, confirm their pathogenicity. $N$. vitifusiforme reported in V. vinifera for the first time in South Africa [30], is now frequently associated with Botryosphaeria dieback in several grape-growing areas worldwide: Spain [31], Mexico [32] and Italy [11].

Despite all the available information concerning Neofusicoccum metabolites, there are no studies on the production of compounds by N. vitifusiforme. In this respect, the production of fatty acids by N. vitifusiforme was investigated. Furthermore, the production of fatty acids was evaluated also for N. paroum isolated by grapevine, previously studied for the production of toxic metabolites [14], in order to compare the fatty acid composition of these two species of Neofusicoccum involved in grapevine diseases.

From the first investigation steps, it was evident that fungi under examination have different metabolic patterns. In fact, crude extracts had significant differences in weight and preliminary tests (i.e., TLC and NMR) confirmed the different composition of the extracts. These findings are not unusual for fungi belonging to different species.

In this work, five different fatty acids and one dicarboxylic acid were detected in the crude extract of the culture filtrate of $N$. vitifusiforme. The most abundant component identified is linoleic acid $(48.2 \%)$. Octadecenoid acids have influence in the fungal virulence because many of them are precursors of jasmonic acid [33], a plant hormone capable of inducing phytotoxic effects [12,22,34-37]. Furthermore, Farmer and Ryan [38] tested the capacity of octadecenoid precursors of jasmonic acid, such as linolenic acid and linoleic acid (which can be converted to linolenic acid by the plant) to be inducers of proteinase inhibitors in tomato, tobacco, and alfalfa leaves. The results suggest that the octadecenoid intermediates may participate in the signaling pathway in response to the pathogen attack and in plant colonization.

Even if in low concentration, N. vitifusiforme also produces azelaic acid, a dicarboxylic acid well-known for its bacteriostatic and bactericidal proprieties against diverse microorganisms [39].

As previously reported [13], four naphthalenone polyketides [i.e., botryosphaerones D and A, isoclerone and (3S,4S)-3,4,5-trihy-droxy-1-tetralone)] were isolated from the examined strains of N. parvum. Each of them showed a different phytotoxicity on grapevine leaves. Moreover, some fatty acids occur in its crude extract and linoleic acid represents the main fatty acid component.

The mixtures of fatty acids produced by the two tested species of Neofusicoccum do not show phytotoxicity on grapevine leaves and probably do not influence the foliar symptoms' expression of GTDs. In fact, the relationship between the botryosphaeriaceous fungi found in the diseased wood and the foliar symptoms observed in some declining vines is still not well understood [6] and the presence of these symptoms has been very sporadic in monitored Sicilian vineyards. So much so that the foliar chlorosis was only observed for plants infected by L. mediterranea strain (B6) and not for plants infected by N. parvum (B19), although both produce an assortment of different metabolites [12,13].

The investigations carried out during the last 10 years induce us to hypothesize that, as well as the kind of cultivar and environmental conditions, the type of secondary metabolite, produced by different botryosphaeriaceous fungi, can also be correlated with foliar chlorosis expression in declining grapevines. 
Author Contributions: M.M.S., S.G., S.B., A.A. conceived and organized the manuscript, and wrote the text, S.G. and S.B. cultivated the fungal strain and performed the pathogenicity assays; M.D.G. and A.A. performed the extraction of culture filtrate and the NMR analysis; M.M.S., D.N. and F.S. performed the GC/MS analysis; F.S., S.B. and A.A. edited and reviewed the manuscript.

Funding: D.N. and A.A. acknowledge the financial support of the Finanziamento delle Attività Base della Ricerca (FFABR) 2017 of the Ministero dell'Educazione e della Ricerca Scientifica (MIUR, Italy). The authors are also grateful for the support of COST Action FA1303: Sustainable control of grapevine trunk diseases. COST Action is supported by the EU RTD Framework program, and ESF provides the COST office through an EC contract.

Conflicts of Interest: The authors declare no conflict of interest.

\section{References}

1. 2017 World Vitiviniculture Situation-OIV Statistical report on World Vitiviniculture. Available online: http:/ / www.oiv.int/public/medias/5479/oiv-en-bilan-2017 (accessed on 1 September 2018).

2. Jayawardena, R.S.; Purahong, W.; Zhang, W.; Wubet, T.; Li, X.; Liu, M.; Zhao, W.; Hyde, K.D.; Liu, J.; Yan, J. Biodiversity of fungi on Vitis vinifera L. revealed by traditional and high-resolution culture-independent approaches. Fungal Div. 2018, 90, 1-84. [CrossRef]

3. Úrbez-Torres, J.R.; Adams, P.; Kamas, J.; Gubler, W.D. Identification, incidence, and pathogenicity of fungal species associated with grapevine dieback in Texas. Am. J. Enol. Vitic. 2009, 60, 497-507.

4. Mugnai, L.; Graniti, A.; Surico, G. Esca (black measles) and brown wood-streaking: Two old and elusive diseases of grapevines. Plant Dis. 1999, 83, 404-418. [CrossRef]

5. Bertsch, C.; Ramírez-Suero, M.; Magnin-Robert, M.; Larignon, P.; Chong, J.; Abou-Mansour, E.; Spagnolo, A.; Clement, C.; Fontaine, F. Grapevine trunk diseases: Complex and still poorly understood. Plant Pathol. 2013, 62, 243-265. [CrossRef]

6. Úrbez-Torres, J.R. The status of Botryosphaeriaceae species infecting grapevine. Phytopathol. Mediterr. 2011, 50, S5-S45.

7. Larignon, P.; Fulchic, R.; Cere, L.; Dubos, B. Observation on black dead arm in French vineyards. Phytopathol. Mediterr. 2001, 40, S336-S342.

8. Yan, J.Y.; Xie, Y.; Zhang, W.; Wang, Y.; Liu, J.K.; Hyde, K.D.; Seem, R.C.; Zang, G.Z.; Wang, Z.Y.; Yao, S.W.; et al. Species of Botryosphaeriaceae involved in grapevine dieback in China. Fungal Divers. 2013, 61, 221-236. [CrossRef]

9. Mondello, V.; Songy, A.; Battiston, E.; Pinto, C.; Coppin, C.; Trotel-Aziz, P.; Clément, C.; Mugnai, L.; Fontaine, F. Grapevine Trunk Diseases: A review of fifteen years of trials for their control with chemicals and biocontrol agents. Plant Dis. 2018, 102, 1189-1217. [CrossRef]

10. Burruano, S.; Mondello, V.; Conigliaro, G.; Alfonzo, A.; Spagnolo, A.; Mugnai, L. Grapevine decline in Italy caused by Lasiodiplodia theobromae. Phytopathol. Mediterr. 2008, 47, 132-136.

11. Mondello, V.; Lo Piccolo, S.; Conigliaro, G.; Alfonzo, A.; Torta, L.; Burruano, S. First report of Neofusiccoccum vitifusiforme and presence of other Botryosphaeriaceae species associated with Botryosphaeria dieback of grapevine in Sicily (Italy). Phytopathol. Mediterr. 2013, 52, 388-396.

12. Andolfi, A.; Basso, S.; Giambra, S.; Conigliano, G.; Lo Piccolo, S.; Alves, A.; Burruano, S. Lasiolactols A and B produced by the grapevine fungal pathogen Lasiodiplodia mediterranea. Chem. Biodivers. 2016, 13, 395-402. [CrossRef]

13. Burruano, S.; Giambra, S.; Mondello, V.; DellaGreca, M.; Basso, S.; Tuzi, A.; Andolfi, A. Naphthalenone polyketides produced by Neofusicoccum parvum, a fungus associated with grapevine Botryosphaeria dieback. Phytopathol. Mediterr. 2016, 55, 197-206.

14. Larignon, P.; Dubos, B. Fungi associated with esca disease in grapevine. Eur. J. Plant Pathol. 1997, 103, 147-157. [CrossRef]

15. Abou-Mansour, E.; Débieux, J.L.; Ramírez-Suero, M.; Bénard-Gellon, M.; Magnin-Robert, M.; Spagnolo, A.; Chong, J.; Farine, S.; Bertsch, C.; L'Haridon, F.; et al. Larignon. Phytotoxic metabolites from Neofusicoccum parvum, a pathogen of Botryosphaeria dieback of grapevine. Phytochemistry 2015, 115, 207-215. [CrossRef]

16. Andolfi, A.; Mugnai, L.; Luque, J.; Surico, G.; Cimmino, A.; Evidente, A. Phytotoxins produced by fungi associated with grapevine trunk diseases. Toxins 2011, 3, 1569-1605. [CrossRef] 
17. Martos, S.; Andolfi, A.; Luque, J.; Mugnai, L.; Surico, G.; Evidente, A. Production of phytotoxic metabolites by five species of Botryosphaeriaceae causing decline on grapevines, with special interest in the species Neofusicoccum luteum and N. parvum. Eur. J. Plant Pathol. 2008, 121, 451-461. [CrossRef]

18. Evidente, A.; Punzo, B.; Andolfi, A.; Cimmino, A.; Melck, D.; Luque, J. Lipophilic phytotoxins produced by Neofusicoccum parvum, a grapevine canker agent. Phytopathol. Mediterr. 2010, 49, 74-79.

19. Ramírez-Suero, M.; Bénard-Gellon, M.; Chong, J.; Laloue, H.; Stempien, E.; Abou-Mansour, E.; Fontaine, F.; Larignon, P.; Mazet-Kieffer, F.; Farine, S.; et al. Extracellular compounds produced by fungi associated with Botryosphaeria dieback induce differential defence gene expression patterns and necrosis in Vitis vinifera cv. Chardonnay cells. Protoplasma 2014, 251, 1417-1426. [CrossRef]

20. Bénard-Gellon, M.; Farine, S.; Goddard, M.L.; Schmitt, M.; Stempien, E.; Pensec, F.; Laloue, H.; Mazet-Kieffer, F.; Fontaine, F.; Larignon, P.; et al. Toxicity of extracellular proteins from Diplodia seriata and Neofusicoccum parvum involved in grapevine Botryosphaeria dieback. Protoplasma 2015, 252, 679-687. [CrossRef]

21. Andolfi, A.; Maddau, L.; Cimmino, A.; Linaldeddu, B.T.; Franceschini, A.; Serra, S.; Basso, S.; Merck, D.; Evidente, A. Cyclobotryoxide, a phytotoxic metabolite produced by the plurivorous pathogen Neofusicoccum australe. J. Nat. Prod. 2012, 75, 1785-1791. [CrossRef]

22. Andolfi, A.; Maddau, L.; Cimmino, A.; Linaldeddu, B.T.; Basso, S.; Deidda, A.; Serra, S.; Evidente, A.; Lasiojasmonates, A.-C. Three jasmonic acid esters produced by Lasiodiplodia sp., a grapevine pathogen. Phytochemistry 2014, 103, 145-153. [CrossRef]

23. Uranga, C.C.; Beld, J.; Mrse, A.; Córdova-Guerrero, I.; Burkart, M.D.; Hernández-Martínez, R. Fatty acid esters produced by Lasiodiplodia theobromae function as growth regulators in tobacco seedlings. Biochem. Biophys. Res. Commun. 2016, 472, 339-345. [CrossRef]

24. Kopka, J.; Schauer, N.; Krueger, S.; Birkemeyer, C.; Usadel, B.; Bergmüller, E.; Dormann, P.; Weckwerth, Y.G.; Fernie, A.R.; Steinhauser, D.; et al. GMD@ CSB. DB: The Golm metabolome database. Bioinformatics 2004, 21, 1635-1638. [CrossRef]

25. AMDIS NET. Available online: http:/ / www.amdis.net/ (accessed on 18 July 2018).

26. Sparkman, O.D.; Penton, Z.E.; Kitson, F.G. Gas Chromatography and Mass Spectrometry: A Practical Guide, 2nd ed.; Elsevier Inc.: Burlington, MA, USA, 2011; ISBN 978-0-12-373628-4978-0-12-373628-4.

27. Nieva-Echevarría, B.; EncarnaciónGoicoechea, M.; Manzanos, J.; Guillén, M.D. A method based on ${ }^{1}$ H NMR spectral data useful to evaluate the hydrolysis level in complex lipid mixtures. Food Res. Int. 2014, 66, 379-387. [CrossRef]

28. Salvatore, M.M.; Nicoletti, R.; Salvatore, F.; Naviglio, D.; Andolfi, A. GC-MS approaches for the screening of metabolites produced by marine-derived Aspergillus. Marine Chem. 2018, 206, 19-33. [CrossRef]

29. Spagnolo, A.; Larignon, P.; Magnin-Robert, M.; Hovasse, A.; Cilindre, C.; van Dorsselaer, A.; Clement, C.; Schaeffer-Reiss, C.; Fontaine, F. Flowering as the most highly sensitive period of grapevine (Vitis vinifera L. cv Mourvèdre) to the botryosphaeria dieback agents Neofusicoccum parvum and Diplodia seriata infection. Int. J. Mol. Sci. 2014, 15, 9644-9669. [CrossRef]

30. van Niekerk, J.M.; Crous, P.W.; Groenewald, J.Z.; Fourie, P.H.; Halleen, F. DNA phylogeny, morphology and pathogenicity of Botryosphaeria species on grapevines. Mycologia 2004, 96, 781-798. [CrossRef]

31. Luque, J.; Martos, S.; Aroca, A.; Raposo, R.; Garcia-Figueres, F. Symptoms and fungi associated with declining mature grapevine plants in northeast Spain. J. Plant Pathol. 2009, 381-390.

32. Candolfi-Arballo, O.; Valenzuela-Solano, C.; Gubler, W.D.; Hernández-Martínez, R. Botryosphaeriaceae species associated with grapevine decline in Mexico. Phytopathol. Mediterr. 2010, 49, 105-106.

33. Schaller, A.; Stintzi, A. Enzymes in jasmonate biosynthesis-structure, function, regulation. Phytochemistry 2009, 70, 1532-1538. [CrossRef]

34. Husain, A.; Ahmad, A.; Agrawal, P.K. (-)-jasmonic acid, a phytotoxic substance from Botryodiplodiatheobromae: Characterization by nmr spectroscopic methods. J. Nat. Prod. 1993, 56, 2008-2011. [CrossRef]

35. Chanclud, E.; Morel, J.B. Plant hormones: A fungal point of view. Mol. Plant Pathol. 2016, 17, $1289-1297$. [CrossRef]

36. Félix, C.; Salvatore, M.M.; DellaGreca, M.; Meneses, R.; Duarte, A.S.; Salvatore, F.; Naviglio, D.; Gallo, M.; Jorrín-Novo, J.V.; Alves, A.; et al. Production of toxic metabolites by two strains of Lasiodiplodia theobromae, isolated from a coconut tree and a human patient. Mycologia 2018, 110, 642-653. [CrossRef] 
37. Tsukada, K.; Takahashi, K.; Nabeta, K. Biosynthesis of jasmonic acid in a plant pathogenic fungus, Lasiodiplodiatheobromae. Phytochemistry 2010, 71, 2019-2023. [CrossRef]

38. Farmer, E.E.; Ryan, C.A. Octadecanoid precursors of jasmonic acid activate the synthesis of wound-inducible proteinase inhibitors. Plant Cell 1992, 4, 129-134. [CrossRef]

39. Fitton, A.; Goa, K.L. Azelaic acid. In Drugs; Springer: Berlin, Germany, 1991; Volume 41, pp. 780-798, ISBN 0012-6667. article distributed under the terms and conditions of the Creative Commons Attribution (CC BY) license (http://creativecommons.org/licenses/by/4.0/). 